\title{
Effects of extraction solvents on cultivars of wheat (PBW-154 and HD-2967) bran antioxidant properties
}

\author{
Nidhi, Devinder Kaur*, Vinita Puranik and Pragya Mishra \\ Centre of Food Technology, University of Allahabad, Prayagraj-211002, Uttar Pradesh, India
}

\begin{tabular}{|c|c|}
\hline Article Info & bstract \\
\hline $\begin{array}{l}\text { Article history } \\
\text { Received } 10 \text { October } 2021 \\
\text { Revised } 26 \text { November } 2021 \\
\text { Accepted } 29 \text { November } 2021 \\
\text { Published Online } 30 \text { December } 2021\end{array}$ & $\begin{array}{l}\text { Wheat is an important source of dietary fiber and natural antioxidant. Two cultivars of wheat bran (PBW- } \\
154 \text { and HD-2967) were analyzed for their proximate, dietary fibre and antioxidant property. The results } \\
\text { indicated that carbohydrates ranged from } 75-78.2 \% \text {, proteins } 11.4-13.2 \% \text {, fats } 2.4-2.7 \% \text { in the wheat } \\
\text { bran of different cultivars, and dietary fiber content was between } 46.7-48.2 \% \text {. Effect of the uses of } \\
\text { different organic solvents (acetone, ethanol and methanol) at various concentrations }(50 \%, 80 \% \text { and }\end{array}$ \\
\hline $\begin{array}{l}\text { Keywords } \\
\text { Wheat bran } \\
\text { Dietary fiber } \\
\text { Solvent polarity } \\
\text { Aantioxidant properties }\end{array}$ & $\begin{array}{l}\text { scavenging activity (DPPH) and ferric reducing antioxidant power) of selected cultivars of wheat bran } \\
\text { extract (PBW-154 and HD-2967) were analyzed by their respective methods. Both cultivars of wheat bran } \\
\text { exhibited the maximum value of antioxidant properties at } 50 \% \text { concentration of solvents followed by } \\
80 \% \text { and } 100 \% \text { concentrations of wheat bran extract. The obtained antioxidants compound and properties } \\
\text { were in the following order (from high to low): } 50 \% \text { ethanol }>50 \% \text { methanol }>50 \% \text { acetone }>70 \% \\
\text { ethanol }>70 \% \text { methanol }>70 \% \text { acetone }>100 \% \text { ethanol }>100 \% \text { acetone }>100 \% \text { methanol }>\text { water for } \\
\text { all the selected cultivars of wheat bran and the statistically significant difference was observed at the level } \\
\text { of } p \geq 0.05 \text {. The study showed that the extraction of antioxidant of selected cultivars of wheat bran in } \\
\text { different organic solvents have significantly different antioxidant properties from each other which } \\
\text { might be due to the polarity of extracting solvents and solubility of the antioxidants from wheat bran. }\end{array}$ \\
\hline
\end{tabular}

\section{Introduction}

As a byproduct derived from roller milling of wheat flour production, wheat bran has high dietary fiber content, which contains $44-50 \%$ of fiber and can be incorporated into food products to alter the nutritional quality of foods (Onipe et al., 2015). Wheat (Triticum aestivum L.) is an important raw material in many countries. The grain is composed of a nutritious inner part, the starchy endosperm, and surrounded by numerous layers of pericep, testa and nucellar epidermis. Processing of wheat separates starchy endosperm from embryo and bran layers into flour and this flour is the base of cereal products. The bran which is obtained as a byproduct of milling is significant source of dietary fiber, tocopherol and bioactive compounds. Several health benefits such as reduced risk of diabetes, degenerative and chronic diseases are well established with the consumption of wheat bran (Wu et al., 2015; Mellen et al., 2009). Bakery products can be supplemented wheat bran for its improved the nutritional and functional value.

Plant antioxidant composites are commonly isolated with solvent extraction method. However, antioxidant activities and extract yields of plant matrix are correlated with the type of recovery solvent, occurrence of diverse antioxidant compounds and polarities of solvent Polar solvents are repeatedly used for the efficient recovery of

Corresponding author: Dr. Devinder Kaur

Centre of Food Technology, University of Allahabad, Prayagraj211002, Uttar Pradesh, India

E-mail: devi_sonu@yahoo.com

Tel.: +91-8853885765

Copyright (C) 2021 Ukaaz Publications. All rights reserved.

Email: ukaaz@yahoo.com; Website: www.ukaazpublications.com polyphenolics from a plant matrix. The commonly employed solvents are aqueous mixtures of organic solvent such as ethanol, methanol, acetone, and ethyl acetate. Methanol and ethanol have been widely used for the recovery of bioactive compounds from various agricultural produce (Aggarwal et al., 2020; Sharma and Chakraborty, 2019; Rehman, 2006). Barley flour phenolic compounds were extracted with ethanol and acetone (Bonoli et al., 2004), whereas maximum rice bran phenolics were recovered from aqueous methanol (Chatha $e t$ al., 2006). Similarly, $80 \%$ methanol was employed for obtaining complex antioxidants from cereal bran (rice and wheat), oat groats and hull (Anwar et al., 2006). Wheat, wheat bran and it's based and supplemented food products were subjected to numerous solvent systems combined with different procedures for the recovery of antioxidants. Extraction efficiency of antioxidants is significantly influenced by number of factors, viz., particle size of sample, solvent to sample ratio, time, temperature and composition of solvent (Kim et al., 2006; Silva et al., 2007). The aim of the work was to examine the effect of three solvents: acetone, ethanol and methanol with different polarities on the antioxidant properties of cultivars of wheat bran.

\section{Materials and Methods}

The two cultivars of wheat bran, i.e., PBW-154 and HD-2967 cultivars were procured from the seed store Alopibag Chungi, Prayagraj, U.P.

\subsection{Proximate analysis}

The proximate composition, viz., moisture, fat, protein, ash, and crude fiber was done by using standard methods of analysis (AOAC, 2016). Carbohydrate content was analyzed using different methods. 


\subsection{Dietary fiber}

Dietary fiber of wheat bran was observed according to the enzymegravimetric methods (AACC, 2000).

\subsection{Antioxidant properties}

\subsubsection{Method of extraction of antioxidant}

Cultivars of wheat bran were isolated by using three solvents (ethanol, methanol and acetone) at different levels (50\%, 80\% and 100\%). One gram of wheat bran was extracted with $5 \mathrm{ml}$ of solvents in a screw-capped tube in the dark condition at ambient temperature for $24 \mathrm{~h}$ and then centrifuged $2000 \mathrm{rpm}$ for $5 \mathrm{~min}$. The collected supernatant was used for further analysis (Moore et al., 2006).

\subsubsection{Total phenolic content}

The total polyphenolic content of the aqueous methanolic extract of wheat bran was done with the 'Folinciocalteu method'. One mlaliquot of the sample extract was taken in a test tube and mixed $5 \mathrm{ml}$. of diluted FC reagent and $4 \mathrm{ml} 7.5 \%$ sodium carbonate solution. Soon after mixing, the test tubes were placed in the dark for $60 \mathrm{~min}$ at ambient temperature and the absorbance was monitored by UVVIS spectrophotometer (model Evolution 600) at $765 \mathrm{~nm}$ against blank as standard. A standard curve was prepared with "Gallic acid" and results were expressed in terms of $\mathrm{mg} / 100 \mathrm{~g}$ of polyphenol present in the sample. Samples were analyzed in triplicates and mean was calculated (Matthaus, 2002).

\subsubsection{Total flavonoids content (TFC)}

The total flavonoids content was analyzed by Boetang et al. (2008). Diluted extract $(2.0 \mathrm{ml})$ was added to $150 \mu \mathrm{l}$ of $5 \%$ sodium nitrite and the mixture was allowed to stand for $5 \mathrm{~min}$. Further, $150 \mu \mathrm{l}$ of 10 $\%$ aluminium chloride was mixed and the mixture was kept for 10 min. After that, $1.0 \mathrm{ml}$ of $1 \mathrm{M}$ sodium hydroxide and $1.2 \mathrm{ml}$ of distilled water was add on to the solution and mixed well. The absorbance was taken at $510 \mathrm{~nm}$ on UV spectrophotometer. Quercetin was used for the standard curve construction $(0.05$ to $0.5 \mathrm{mg} / \mathrm{ml})$. The results were demonstrated as mg quercetin equivalent $(\mathrm{QE}) / \mathrm{g}$ of flour.

\subsubsection{Per cent free radical scavenging activity (DPPH activity)}

The DPPH (2,2-diphenyl 1-pycril hydrazil) radical scavenging activity of wheat bran extracts was measured according to the method given by Sanja et al. (2009) with slight modification. $3 \mathrm{ml}$ of extracts of cereal bran of each solvent was mixed with $2 \mathrm{ml}$ of $0.15 \mathrm{mM}$ methanolic DPPH solution. The mixture was shaken and decrease in absorbance was measured at $515 \mathrm{~nm}$ with the help of UV/VIS spectrophotometer after $15 \mathrm{~min}$ incubation at room temperature. DPPH solution was used as control.

Control use methanol as blank solution.

$$
\% \text { free radical scavenging activity }=\frac{\left(\mathrm{A}_{\text {control }}-\mathrm{A}_{\text {sample }}\right)}{\mathrm{A}_{\text {control }}} \times 100
$$

\subsubsection{Ferric reducing antioxidant power assay}

$200 \mu \mathrm{l}$ of solvent extract of each sample was mixed with $1.3 \mathrm{ml}$ of the FRAP reagent. FRAP reagent, consisted of $0.3 \mathrm{M}$ acetate buffer $(\mathrm{pH}$ 3.6), $10 \mathrm{mM}$ TPTZ in $40 \mathrm{mMHCl}$ and $20 \mathrm{mM} \mathrm{FeCl} 3$ in a ratio of 10:1:1 (v/v/v). After mixing with FRAP reagent, samples were incubated for $30 \mathrm{~min}$ at $37^{\circ} \mathrm{C}$ and then absorption was measured against blank at 595 using a spectrophotometer. FRAP values, expressed as mmol of $\mathrm{Fe}$ (II) equivalent per $\mathrm{g}$ flour (Sutharut and Sudarat, 2012).

\subsection{Statistical analysis}

The data collected from the proximate, dietary fiber and antioxidant analyses were presented as means of triplicates. LSD values were calculated for significant data to find significant difference in proximate composition and dietary fiber. The solvent data were subjected to one-way analysis of variance using SPSS statistical software version 20.0. The mean was separated by applying the Duncan Multiple Range test at $95 \%$ confidence level $(p<05)$.

\section{Results}

\subsection{Proximate composition}

Proximate analysis of wheat bran which was generated during the milling process showed that, this ingredient has important nutritional value since it is rich in fiber and protein, while fat and ash as minor components. The proximate composition of two different wheat cultivars bran (PBW-154 and HD-2967) is presented in Table 1.The proximate composition varied significantly $(p<0.05)$ among both cultivars of wheat bran. The ash content, moisture, protein, crude fat and crude fibre contents of wheat bran (HD-2967 and PBW-145) ranged from 3.0 to $3.2 \% ; 4.77$ to $6.2 \% ; 11.4$ to $13.2 \% ; 2.7$ to $2.4 \%$; 7.3 to $10.2 \%$, respectively. In PBW-154 cultivar of wheat bran has the highest value of chemical composition compared to HD-2967 cultivar of wheat bran. Ranhotra et al. (1994) reported the ash content of wheat bran was in range from 5.2 to $5.5 \%$. Protein content of wheat bran was 14 to $16 \%$ as reported by Halverson and Zeleny (1988). Tian et al. (2020) reported that the proximate composition (protein, fat, ash) of wheat bran that was in range from 17.66 to $17.81 ; 2.89$ to $4.16 \%$; and 17.58 to $24.74 \%$. The ash content of selected wheat bran cultivars was similar as descibed by D'hoe $e t$ al. (2018). Similar results were reported for fat percentage of wheat bran by Curti et al. (2013). Elawad, et al. (2016) reported moisture, fat, fiber, and carbohydrate contents which were $7.8 \%, 5.6 \%, 9.6 \%$, $61.3 \%$ in wheat bran, respectively. These compositions were found close to the existing value. Thus, the results of proximate analysis of present study are in line with previous studies. The variation in each nutritional content among all cultivars of wheat bran is due to environmental related factors like maturity period, climate, location, temperature, fertility, diseases, pest exposure, climate, soil condition, etc. (Zheng and Wang, 2001).

\subsection{Dietary fiber}

Dietary fiber is resistive to enzymatic digestion which typically includes non-starch polysaccharides (cellulose, hemicellulose), oligosaccharides (pectic substances, gums, mucilages) and a lignin. Dietary fibre content of selected cultivars of wheat bran (PBW-154 and HD-2967) were analyzed and the results are given in the Table 2. Dietary fibre values was found significantly $(p<0.05)$ different among both cultivars of wheat bran. The soluble dietary fibre, insoluble dietary fibre and total dietary fibre contents of wheat bran (HD2967 and PBW-145) ranged from 4.8 to $5.7 \%, 41.9$ to $42.5 \%$ and 46.7 to $48.2 \%$, respectively. In PBW-154 cultivar of wheat bran has the higher value of dietary fibre content compared to HD-2967 cultivar of wheat bran.Importance of consuming dietary fiber has increased owing to its relation with the reduction of blood cholesterol level, 
lower inulin demand and improved laxative properties. The recommended daily intake of total dietary fiber is ranges from 30 to $38 \mathrm{~g} /$ day for male and 21 to $26 \mathrm{~g} /$ day for female (Gomez et al., 2013). Insoluble dietary fibers helping human well being by stimulating the growth of the intestinal microflora, increase the fecal execration and reducing the intestinal transit (Gomez et al., 2011). Carson and Edwards (2009) reported the dietary fibre values of the whole wheat ranges from $11.6 \%-12.7 \%$ dry weight.

Table 1: Proximate composition of wheat bran of selected cultivars HD-2967 and PBW-154

\begin{tabular}{|l|c|c|c|c|c|c|}
\hline $\begin{array}{l}\text { Cultivars of } \\
\text { wheat bran }\end{array}$ & Moisture (\%) & Protein (\%) & Fat (\%) & Crude fiber (\%) & Ash content (\%) & Carbohydrates (\%) \\
\hline PBW-154 & $6.20^{\mathrm{b}} \pm 0.4$ & $13.2^{\mathrm{b}} \pm 0.5$ & $2.4^{\mathrm{a}} \pm 0.3$ & $10.2^{\mathrm{b}} \pm 0.3$ & $3.2^{\mathrm{b}} \pm 0.1$ & $75.0^{\mathrm{b}} \pm 2.1$ \\
HD-2967 & $4.77^{\mathrm{a}} \pm 0.5$ & $11.4^{\mathrm{a}} \pm 0.5$ & $2.7^{\mathrm{a}} \pm 0.2$ & $7.3^{\mathrm{a}} \pm 0.4$ & $3.0^{\mathrm{a}} \pm 0.2$ & $78.2^{\mathrm{a}} \pm 1.2$ \\
\hline
\end{tabular}

Values with different superscript in column are significantly $(p<0.05)$ different.

Table 2: Dietary fibre content of wheat bran of selected cultivars (HD-2967 and PBW-154)

\begin{tabular}{|l|c|c|c|}
\hline Sample & $\begin{array}{c}\text { Soluble } \\
\text { dietary } \\
\text { fiber }(\boldsymbol{\%})\end{array}$ & $\begin{array}{c}\text { Insoluble } \\
\text { dietary } \\
\text { fiber }(\boldsymbol{\%})\end{array}$ & $\begin{array}{c}\text { Total } \\
\text { dietary } \\
\text { fiber }(\boldsymbol{\%})\end{array}$ \\
\hline PBW-154 & $5.7^{\mathrm{b}} \pm 0.2$ & $42.5^{\mathrm{a}} \pm 1.5$ & $48.2^{\mathrm{b}} \pm 2.1$ \\
HD-2967 & $4.8^{\mathrm{a}} \pm 0.2$ & $40.4^{\mathrm{b}} \pm 1.0$ & $45.2^{\mathrm{a}} \pm 1.1$ \\
\hline
\end{tabular}

Values with different superscript in column are significantly $(p<0.05)$ different.

3.3 Effect of extraction solvents on antioxidants compounds (TPC and flavonoids) and antioxidant activity (DPPH and FRAP) from bran of wheat cultivars

The polyphenolics form complexes with other molecules like polysaccharides, protein, pigment such as anthocyanin and chlorophyll. Hence, for the recovery of polyphenolic compounds, appropriate solvent is required which helps in maximum dissolution of these compounds (Michalak et al., 2017). In the present study, different solvent extracts were used for extraction of total phenolics and differences in values were observed with increased in the polarity. The isolation of polyphenolics from different food sample is subjective to the polarity of extracting solvents and solubility of these compounds in the solvent (Nawaz et al., 2020).

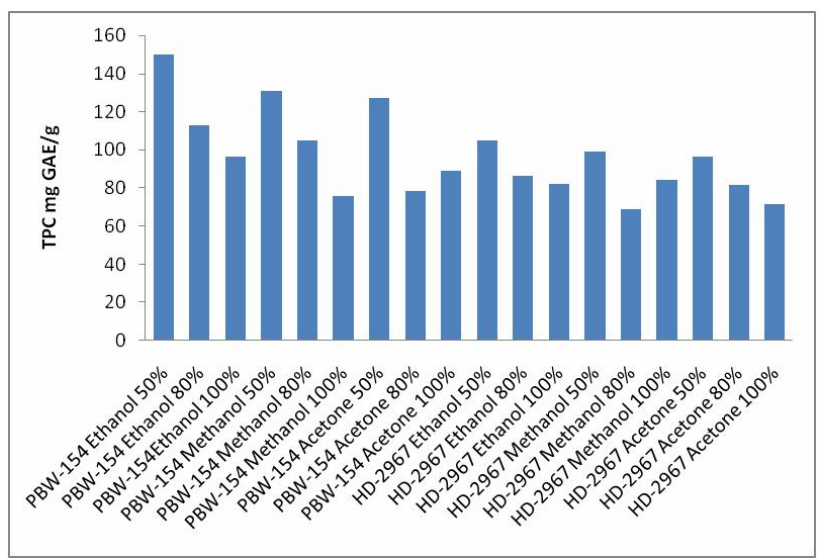

Figure 1: Effect of solvents on total phenolic content of cultivars of wheat bran (PBW-154 and HD 2967).

The obtained TPC values were in the following order (from high to low): $50 \%$ ethanol $>50 \%$ methanol $>50 \%$ acetone $>70 \%$ ethanol $>$ $70 \%$ methanol $>70 \%$ acetone $>100 \%$ ethanol $>100 \%$ acetone $>$ $100 \%$ methanol $>$ water for all selected wheat bran cultivars and the statistical significant difference was observed at the level of $p>0.05$. The total phenolic content of wheat cultivars in different solvents at various concentrations of extracts varied from 71.3 to $150 \mathrm{GAE} \mathrm{mg} /$ $\mathrm{g}$ (Figure 1). The highest total phenolic was obtained with $50 \%$ ethanol solvents in cultivar of PBW-154 wheat bran, followed by methanol and acetone at $80 \%$ and $100 \%$ concentration, respectively.

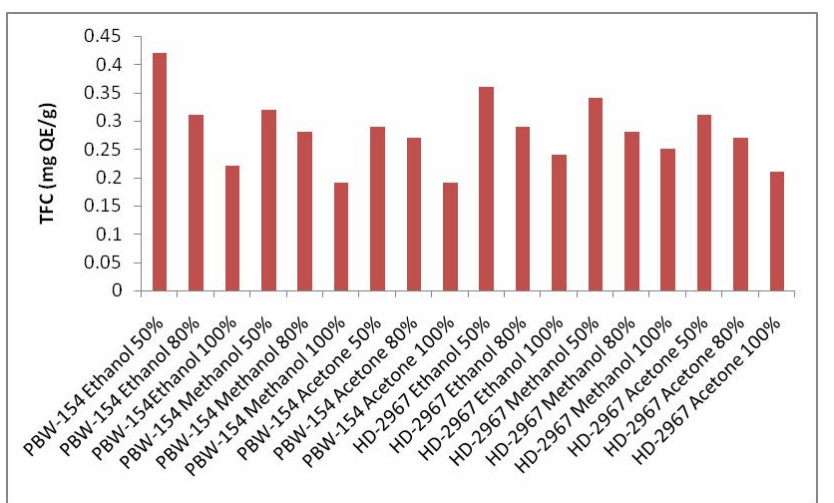

Figure 2: Effect of solvents on total flavonoid content of cultivars of wheat bran (PBW-154 and HD 2967).

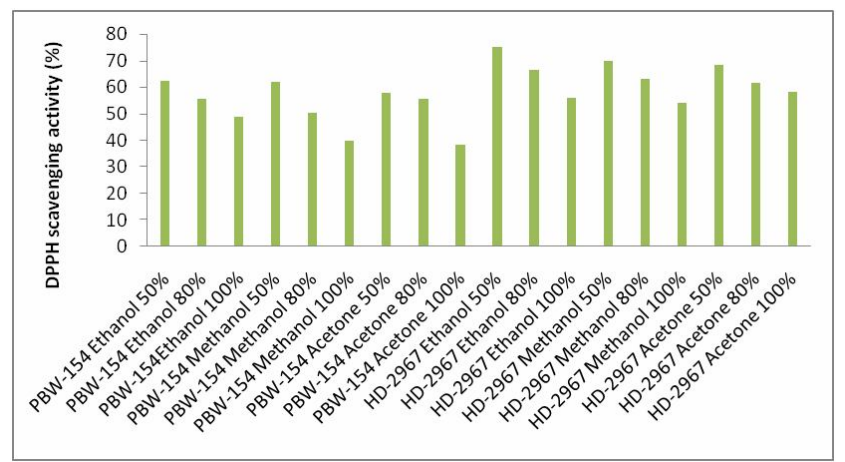

Figure 3: Effect of solvents on DPPH scavenging activity \% of cultivars of wheat bran (PBW-154 and HD 2967).

Flavonoids are significant secondary metabolites of plant which include condensed tannins, flavanols and flavones. Various studies advise that the consumption of flavonoid-rich foods guard humans against diseases associated with oxidative stress. In order to estimate the potential effect of solvent on the amount of TFC, the wheat bran was subjected to different solvents for the extraction of flavanoids. For both the wheat cultivars, significant difference $(p<0.05)$ in total antioxidant activity was analyzed between the different solvents. These results showed that potential influence of extracting solvents 
on total flavonoid content for the tested wheat bran extract. The range of TFC in wheat bran cultivars at different solvents was ranged from 0.19 to $0.42 \mathrm{mg}$ Eqv/g for wheat bran. The results displayed that $50 \%$ ethanol containing higher level of flavonoids than methanol and acetone (Figure 2). The TFC values were highest for cultivar PBW-154 (0.42 mg Eqv/g of bran) at 50\% ethanol, followed by methanol and acetone at $80 \%$ and $100 \%$ solvents. Results showed that $50 \%$ ethanol was the best medium for the extraction of flavonoid content. The statistical significant $(p<0.05)$ difference in TFC value of wheat bran in different solvents is obtained and ranged from 2.78 to $22.04 \mathrm{mg}$ QCE/g in decreasing order, i.e., $50 \%$ ethanol $>50 \%$ methanol $>50 \%$ acetone $>80 \%$ ethanol $>80 \%$ methanol $>80 \%$ acetone $>100 \%$ ethanol $>100 \%$ methanol $>100 \%$ acetone $>$ water. Present analyzed results are in harmony with those of Safaa $e t$ al. (2014) who revealed that TFC content was found maximum in 50\% ethanol extract of wheat bran.

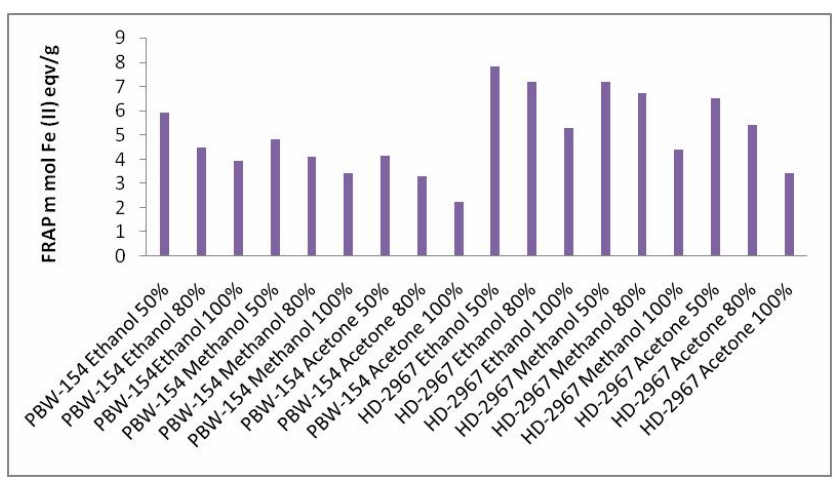

Figure 4: Effect of solvents on FRAP values of cultivars of wheat bran (PBW-154 and HD 2967).

It is usually linked that free radicals formed in the body raised the incidence of degenerative diseases and cancers. Dietary antioxidants help in prevention of chronic illness by reactive oxygen species. Therefore, it is important to determine the radical scavenging effect of antioxidants in cereals. DPPH radicle has the ability to scavenge reactive oxygen species such as hydrogen peroxide, hydroxyl radical and superoxide radical anion. Effect of extracts of both cultivars of wheat bran (PBW-154 and HD-2967) at different concentration of solvents is presented in Figure 3. The DPPH values were statistically ( $p>0.05$ ) highest in HD-2967 at 50\% concentration of ethanol. Results showed a decreasing order in \% DPPH activity, i.e., $50 \%$ ethanol $>$ $50 \%$ methanol $>50 \%$ acetone $>80 \%$ ethanol $>80 \%$ methanol $>80 \%$ acetone $>100 \%$ ethanol $>100 \%$ methanol $>100 \%$ acetone $>$ water. The above results were supported by Safaa et al. (2014), who found maximum radical DPPH activity of wheat bran in $70 \%$ ethanol extract as compared to methanol and acetone extract.

DPPH activities of both cultivars of wheat bran extracts at different concentrations in various solvents showed the similar trend in results as it was seen in TPC and TFC content. Percentage of DPPH activity of both cultivars of wheat bran was found between 38 to $75 \%$. Results showed that the extracting solvent, cultivars and percentage of solvents and water significantly $(p<0.05)$ altered the antioxidant property of all the selected wheat bran cultivars. For both the wheat varieties, significant difference $(p<0.05)$ in total antioxidant activity was observed between the different solvents (Figure 3 ). These results are in harmony with Safaa et al. (2014) and D. Lope et al. (2019).
The above results were supported by those of Safaa et al. (2014), who found maximum radical DPPH activity $\%$ of wheat bran in $70 \%$ ethanol extract as compared to methanol and acetone extract.

The FRAP values of the extracts are presented in Figure 4, for both cultivars of wheat bran (PBW-154 and HD-2967). The maximum antioxidant activity was found in cultivar HD-2967 wheat bran at $50 \%$ ethanol, followed by methanol and acetone at $80 \%$ and $100 \%$ concentration. The FRAP values of cultivars of wheat bran extracts are ranked as follows: $50 \%$ ethanol $>50 \%$ methanol $>50 \%$ acetone $>80 \%$ ethanol $>80 \%$ methanol $>80 \%$ acetone $>100 \%$ ethanol $>$ $100 \%$ methanol $>100 \%$ acetone $>$ water. The values of FRAP activity differ significantly $(p<0.05)$ in wheat bran in different solvents of various concentrations and was ranged from 2.25 to $7.8 \mathrm{~m} \mathrm{M} \mathrm{Fe}$ (II)/ $/ g$. Minimum FRAP values were reported in cultivar of PBW-154 wheat bran at $100 \%$ concentration of acetone $2.25 \mathrm{~m} \mathrm{Mol}$ (Fe(II) eqv)/g. Results presented that the isolating solvent, concentration and cultivars was significantly $(p<0.05)$ altered the FRAP assay estimations of both cultivars of wheat bran (Figure 4). Brewer et al. (2014) studied the Ferric reducing antioxidant power in different particle size of wheat bran which ranges from $8.93 \mathrm{~m} \mathrm{Mol}$ (Fe (II) eqv)/g to $23.84 \mathrm{~m} \mathrm{Mol}$ (Fe (II) eqv)/g. These values are similar to present study.

\section{Discussion}

Cereals contain variety of compounds showing antioxidant properties. Different methods have been developed to determine the antioxidant property of different cultivars of wheat bran (Moore et al., 2006). The recovery of the compounds is dependent on types of solvent and on the solubility of the antioxidant compounds in solvents used for the extraction. Thus, the isolation of polyphenolic compounds is reliant on the solvents of different polarities. The difference in the isolation efficiency of antioxidants and bioactive compounds from wheat bran might be due to diverse obtainability of extractable components because of its varied chemical components of the cereals. The amount of the antioxidant components that can be extracted is mainly affected by the cultivars, environmental factor, cropping, harvesting, etc, which probably may vary from sample-to-sample. Solvent such as aqueous ethanol are mostly used for the extraction of phenolic compounds from plant matrix (Patthamakanokporn et al., 2008; Mc-Cook Russell et al., 2012; Bahorun et al., 2004), as plant phenolics have the ability to dissolve in aqueous ethanol. Hence, it is important to select suitable solvent for the isolation and optimization of polyphenolics and other bioactive compounds. Therefore, the selection of a right solvent is the relevant steps in optimizing the recovery of polyphenolics and other antioxidant compounds from a sample. Nihal et al. (2005) reported that 50\% acetone has shown maximum polyphenolic content of black mate tea, followed by 80 and $100 \%$ and these results were found similar to the present study. Safaa et al. (2014) reported the phenolic content of wheat flour and its bran at various conc. (50\% acetone and $70 \%$ ethanol and methanol) and found that phenolic content was found to be highest in $50 \%$ acetone. Results of discussed studies were in compliance with the results reported in the current study.

The concentration of flavonoid content, DPPH and FRAP activity in both cultivars of wheat bran extracts depends on the various concentration of aqueous solvents (Min and Chun-Hao, 2005). Brewer et al. (2014) also reported the extraction of TFC in wheat bran at different particle size $(0.177-0.206 \mathrm{mg} / \mathrm{gm}$ of sample). This 
showed that extraction process may modify the overall efficiency of antioxidant extraction. Therefore, careful selection of solvent is important to maximize the recovery of antioxidants and polyphenolics from wheat bran.

\section{Conclusion}

The present study has explore the suitability of different extracting solvents with different polarities, as a most relevant step in optimizing the recovery of the total phenolic content and total flavonoid content as well as other antioxidants with potential pharmacological properties and health benefits. The study revealed that extraction of total phenolic, flavonoid content and total antioxidants activity in terms of free radical scavenging activity and ferric reducing power were found maximum in the $50 \%$ ethanol followed by $50 \%$ methanol, and acetone, respectively. Extractions of polyphenolic compound of both cultivars of wheat bran were strongly correlated with polarity of solvents (ethanol, methanol and acetone). Thus, suitable solvent of appropriate polarity is important for the isolation and optimization of wheat bran plenolics and antioxidant activity.

\section{Conflict of interest}

The authors declare no conflicts of interest relevant to this article.

\section{References}

AACC (2000). Approved Methods of American Association of Cereal Chemists, tenth ed", American Association of Cereal Chemists, Inc., Minnesota, USA.

Aggarwal, S.; Tripathi, S.; Arshi and Mishra, N. (2020). Nutritional composition and antioxidant profiles of Nigella sativa L. seeds. Ann. Phytomed., 9(2):207-214

Anwar, F.; Jamil, A.; Iqbal, S. and Sheikh, M.A. (2006). Antioxidant activity of various plant extracts under ambient and accelerated storage of sunflower oil. Grasas Aceites Sevilla, 57:189-197.

AOAC Official Methods of Analysis. (2016). Association of Official Analytical Chemists, Inc., $20^{\text {th }}$ Edn, Arlington.

Bahorun, T.; Ramma, L. A.; Crozier, A. and Aruoma, O. I. (2004). Total phenol, flavonoid, proanthocyanidin and vitamin $\mathrm{C}$ levels and antioxidant activities of mauritian vegetables. J. Sci. Food Agric., 84 (12):15531561 .

Boateng, J.; Verghese, M.; Walker, L.T. and Ogutu, S. (2008). Effect of processing on antioxidant contents in selected dry beans (Phaseolus spp.). Food Sci. Technol., 41:1541-1547.

Bonoli, M.; Verardo, V.; Marconi, E. and Caboni, M.F. (2004). Antioxidan phenols in barley (Hordeum vulgare L.) flour: Comparative spectrophotometric study among extraction methods of free and bound phenolic acids. J. Agric. Food Chem., 52:5195-5200.

Brewer, R. L.; Kubola, J.; Siriamornpun. S.; Herald, J.T. and Shi, Y. (2014). Wheat bran particle size influence on phytochemical extractability and antioxidant properties. Food Chem., 152:483-490.

Carson, G.R, Edwards N.M. (2009). Criteria of wheat and flour quality. In: Khan K, Shewry P, editors. Wheat Chemistry and Technology. St Paul, MN: Am. Assoc. Cereal Chem., pp:97-118.

Chatha, S. A. S.; Anwar, F.; Manzoor, M. and Bajwa, J.R. (2006). Evaluation of the antioxidant activity of rice bran extracts using different antioxidant assays. Grasas Aceites Sevilla, 57:328-335.

Curti, E.; Carini, E.; Bonacini, G.; Tribuzio, G. and Vittadini, E. (2013). Effect of the addition of bran fractions on bread properties. J. Cereal Sci., 57:325-332.
D’hoe, K.; Conterno, L.; Fava, F.; Falony, G.; Vieira-Silva, S.; Vermeiren, J.; Tuohy, K. and Raes, J. (2018). Prebiotic wheat bran fractions induce specific microbiota changes. Front Microbiol., 9:31.

Elawad, R. M. O.; Yang, T. A.; Ahmed, A. H. R.; Ishag, K. E. A.; Mudawi, H. A. and Abdelrahim, S. M. K. (2016). Chemical composition and functional properties of wheat bread containing wheat and legumes bran. Int. J. Food Sci. Nutr., 10-15 (5):2455-4898.

Gomez, A. V; Buchner, D; Tadini, C.C.; Anon, M.C. and Puppo, M. C. (2013). Emulsifiers: Effects on quality of fiber enriched wheat bread. Food Bioproc. Technol., 6(5):1228-1239.

Gomez, M.; Jimenez, S.; Ruiz, E. and Oliete, B. (2011). Effect of extruded bran on dough rheology and bread quality. LWT-Food Sci. Technol., 44:2231-2237.

Halverson, J. and Zeleny, L. (1988). Criteria of wheat quality. In Wheat Chemistry and Technology, Vol. I, 3rd Ed. (Y. Pomeranz, ed.) pp. 15-45, American Association of Cereal Chemists, St. Paul, Minnesota.

Kim, K.; Tsao, R.; Yang, R. and Cui, S. W. (2006). Phenolic acid profiles and antioxidant activities of wheat bran extracts and the effects of hydrolysis conditions. Food Chem., 95:466-473.

Michalak, I.; Leska B.; Schroeder, G.; Górka, G.; Korzeniowska, K.; Lipok, J.; Wieczorek, P.; Edward R.; Rados ${ }^{3}$ aw W.; Agnieszka D.I.; Henryk G. and Katarzyna, C. (2017). Valuable natural products from marine and freshwater macroalgae obtained from supercritical fluid extracts. J. Appl. Phycol., 30:591-603.

Moore, J.; Hao, Z.; Zhou, K.; Luther, M.; Costa, J. and Yu, L.(2006). Carotenoid, tocopherol, phenolic acid and antioxidant properties of Marylandgrown soft wheat. J. Agric. Food Chem., 53(17):6649-6657

Matthaus. B. (2002). Antioxidant activity of extracts obtained from residues of different oil seeds. J. Agri. Food Chem., 50:3444-3452.

Moore, J.; Cheng, Z; Su, L. and Yu, L. (2006). Effects of solid-state enzymatic treatments on the antioxidant properties of wheat bran. J. Agric. Food Chem., 54:9032-9045.

Mc-Cook-Russell, K. P.; Nair, M. G.; Facey, P. C. and Bowen-Forbes, C. S. (2012). Nutritional and nutraceutical comparison of Jamaican Psidium cattleianum (Strawberry guava) and Psidium guajava (Common guava) fruits. Food Chem., 134(2):1069-1073.

Min, G. and Chun-Zhao, L. (2005). Comparison of techniques for the extraction of flavonoids from cultured cells of Saussurea medusa Maxim. World J. Microb. Biot., 21:1461-1463.

Nawaz, H.; Shad, M. A.; Hina, N. R. and Ullah, A. N. (2020) Effect of solvent polarity on extraction yield and antioxidant properties of phytochemicals from bean (Phaseolus vulgaris) seeds. Braz. J. Pharm. Sci., 56:1-9

Noort, M.W.J.; Haaster, D.V.; Hemery Y.; Schols, H.A. and Hamer, R. J. (2010). The effect of particle size of wheat bran fractions on bread quality: Evidence for fiber-protein interactions. J. Cereal Sci., 52:59-64.

Nihal, T.; Ferda. S. and Velioglu, Y. S. (2005). Effects of extraction solvents on concentration and antioxidant activity of black and black mate tea polyphenols determined by ferrous tartrate and Folin-Ciocalteu methods. Food Chem., 99:835-841.

Onipe, O. O.; Jideani, A. I. O. and Beswa. D. (2015). Composition and functionality of wheat bran and its application in some cereal food products. Int. J. Food Sci. Technol., 50:2509-2518.

Patthamakanokporn, O.; Puwastien, P.; Nitithamyong, A. and Sirichakwal, P. P. (2008). Changes of antioxidant activity and total phenolic compounds during storage of selected fruits. J. Food Comp. Anal., 21(3):241-248. 
Ranhotra, G.S.; Gelroth, J.A.; Glaser, B.K. and Reddy, P.V. (1994). Nutritional profile of a fraction from air classified bran obtained from hard red wheat. J. Nutr., 71:321-323.

Rehman, Z.U. (2006). Citrus peel extract: A natural source of antioxidant. Food Chem., 99:450-454.

Safaa, S.; Abozed, M.; El-kalyoubi, A.; Abdelrashid, M. and Salama,F. (2014). Tota phenolic content and antioxidant activities of various solvent extracts from whole wheat and wheat bran. Annals Agric. Sci., 59 (1):63-67.

Sanja.S.D.; Sheth.N.; Patel. N. K. and D. Patel, B.(2009). Characterization and evaluation of antioxidant activity of Portuluca oleracea. Int. J. Pharma Sci., 1:74-84.

Sharma, S. and Chakraborty, D. (2019). Antimicrobial and antioxidant activity of Coriandrum sativum L. Ann. Phytomed., 8(1):135-139.
Silva, E. M.;Rogez, H.; Larondelle, Y. (2007). Optimization of extraction of phenolic from Inga edulis leaves using response surface methodology. Sep.Purif. Technol., 55:381-387.

Sutharut, J. and Sudarat, J. (2012). Total anthocyanin content and antioxidant activity of germinated colored rice. Inter. Food Res. J., 19(1):215221.

Tian, S. Q.; Li, Y. H.; Chen, Z. C. and Qiao, Y. F. (2017). Effects of layering milling technology on distribution of green wheat main physicochemical parameters. J. Food Quality, 7:1-7.

Wu, H.; Flint, A. J. and Qi. Q. (2015). Association between dietary whole grain intake and risk of mortality: Two large prospective studies in US men and women. JAMA Intern. Med., 175:373-384.

Zheng, W. and Wang, S. Y. (2001). Antioxidant activity and phenolic compounds in selected herbs. J. Agri. Food Chem., 49:5165-70. 